\title{
Efeitos do Tempol (4-hidroxi-tempo) sobre a plasticidade sináptica após esmagamento de raízes ventrais na interface do SNC e SNP
}

\author{
Caroline B. Teles (IC), Aline B. Spejo (PG), Alexandre L.R. de Oliveira (PQ). \\ Resumo \\ A lesão medular consiste em uma importante causa de incapacidade neurológica após um trauma, podendo \\ resultar em avulsão, tração ou esmagamento das raízes da medula espinal. O presente estudo analisou o \\ efeito do Tempol na plasticidade sináptica e excitotoxicidade glutamatérgica após esmagamento de raízes \\ ventrais em ratos adultos. A administração de Tempol com dosagem de $24 \mathrm{mg} / \mathrm{Kg}$ não foi capaz de \\ minimizar a perda de inputs sinápticos excitatórios e inibitórios na superfície dos motoneurônios \\ axotomizados.
}

Esmagamento, Tempol, plasticidade sináptica.

\section{Introdução}

Abrupta tração entre o pescoço e ombro, decorrente de lesões obstétricas e acidentes de moto podem levar ao estiramento, esmagamento ou avulsão de raízes da medula espinal gerando importantes perdas funcionais. A fisiopatologia da lesão inclui alterações das sinapses nos neurônios lesados, excitotoxicidade glutamatérgica, reação glial e liberação de espécies reativas de oxigênio (ROS) e nitrogênio (NOS) ${ }^{1}$. O sistema nervoso central (SNC) é facilmente danificado pelas ROS e NOS devido à sua grande constituição lipídica e ausência de mecanismos de defesa antioxidantes eficientes. Assim, a eficácia neuroprotetora de agentes farmacológicos com atividade antioxidante em lesões do SNC tem sido extensamente estudada ${ }^{2}$. Dentre as drogas antioxidantes destaca-se 0 Tempol, já demonstrado em estudos anteriores por possuir efeito neuroprotetor após lesão traumática do nervo isquiático em ratos neonatos, aumentando a sobrevivência dos motoneurônios medulares $^{2}$. O presente estudo teve como objetivo analisar o efeito do Tempol na plasticidade sináptica e excitotoxicidade glutamatérgica, após esmagamento das raízes ventrais $L 4$, $L 5$ e $L 6$ em ratos adultos fêmeas da linhagem Sprague-Dawley

\section{Resultados e Discussão}

Os animais foram separados em dois grupos experimentais $(n=5$, por grupo experimental): (1) esmagamento de raízes ventrais L4, L5 e L6 e administração intraperitoneal de solução salina (PBS) e (2) esmagamento de raízes ventrais $L 4$, L5 e L6 e administração intraperitoneal de Tempol $(24 \mathrm{mg} / \mathrm{Kg})$. O Tempol foi diluído em solução salina e administrado 10 minutos, 6 horas e 24 horas após a lesão e a cada 48 horas decorrentes da última aplicação até o término dos 14 dias. A administração de solução salina seguiu os mesmos tempos de aplicação. Através de técnica de imunoistoquímica, 2 semanas após a lesão, analisou-se a expressão de sinaptofisina, GAD65 e VGLUT, respectivamente marcadores de sinapses, sinapses GABAérgicas e sinapses glutamatérgicas. Observou-se redução na imunomarcação na superfície dos motoneurônios lesionados em relação a motoneurônios não lesionados para sinaptofisina (redução de $38 \%$ ), GAD65 (30\%) e VGLUT1 (35\%). Isso se deu em igual proporção nos dois grupos experimentais. Dessa forma, o Tempol não foi capaz, na presente dose, de minimizar a perda de inputs sinápticos na soma dos motoneurônios axotomizados, sejam eles excitatórios ou inibitórios, após o esmagamento de raízes ventrais na concentração e período de aplicação utilizado neste estudo.

\section{Conclusões}

O esmagamento de raízes ventrais leva a uma extensiva perda sináptica nos corpos celulares dos neurônios afetados. $O$ tratamento com Tempol na dose $24 \mathrm{mg} / \mathrm{Kg}$ não foi capaz de minimizar a perda desses inputs, sejam eles excitatórios ou inibitórios. Dessa forma, a próxima etapa desse projeto visa encontrar a concentração ótima de Tempol a ser utilizado nesse tipo de lesão para fins neuroprotetivos.

\section{Agradecimentos}

À Fundação de Amparo à Pesquisa do Estado de São Paulo (Fapesp) pelo apoio financeiro.

\footnotetext{
${ }^{1}$ Leal, M.B. Spinal cord injury: From inflammation to glial scar. Surgical neurology international, 2011, 112, 2

${ }^{2}$ Chiarotto, G. B., Drummond, L., Cavarretto, G., Bombeiro, A. L., \& de Oliveira, A. L. R. Neuroprotective effect of tempol (4 hydroxytempo) on neuronal death induced by sciatic nerve transection in neonatal rats. Brain Research Bulletin. 2014, 106, 1-8.
} 